\title{
Information, knowledge and wisdom: groundwork for the normative evaluation of digital information and its relation to the good life
}

\author{
Edward H. Spence
}

Published online: 9 February 2011

(C) The Author(s) 2011. This article is published with open access at Springerlink.com

\begin{abstract}
This paper provides a general philosophical groundwork for the theoretical and applied normative evaluation of information generally and digital information specifically in relation to the good life. The overall aim of the paper is to address the question of how Information Ethics and computer ethics more generally can be expanded to include more centrally the issue of how and to what extent information relates and contributes to the quality of life or the good life, for individuals and for society. To answer that question, the paper explores and provides by way of a theoretical groundwork for further research, the concept of wisdom understood as a type of meta-knowledge as well as a type of meta-virtue, which can enable one to both know in principle what a good life is and how to successfully apply that knowledge in living such a life in practice. This answer will be based on the main argument presented in this paper that the notion of wisdom understood as being at once a meta-epistemological, meta-axiological and meta-eudemonic concept, provides the
\end{abstract}

This paper is part of a larger research project that I began in the Department of Philosophy at the University of Twente, Netherlands, 2006-2009, as a Research Fellow of a VICI International Research Project for the Evaluation of New Media in Relation to the Good Life. The project funded by the National Dutch Research Council (NWO) was led by Professor Philip Brey, Head of the Department of Philosophy at the University of Twente, Netherlands.

E. H. Spence $(\square)$

Centre for Applied Philosophy and Public Ethics (CAPPE), Charles Sturt University, Panorama Avenue, Bathurst, NSW 2795, Australia

e-mail: espence@csu.edu.au

E. H. Spence

3TU. Centre for Ethics and Technology,

University of Twente, Twente, Netherlands essential conceptual link between information on the one hand and the good life on the other. If, as we are told, this is the Age of Information, both the theoretical examination and analysis of the question of how information relates to the good life and the provision of an adequate answer to that question are essential for developing a deeper understanding of how to evaluate the theoretical and practical implications and ramifications of information for the good life, for individuals and societies generally.

Keywords Information - Digital information ·

Knowledge $\cdot$ Wisdom $\cdot$ Dual obligation information theory · Epistemology · Ethics · Axiology · Eudemonia · Virtues - The good life

\section{Introduction}

Where is the Life we have lost in living?

Where is the wisdom we have lost in knowledge?

Where is the knowledge we have lost in information?

T. S. Eliot Choruses from The Rock (1934)

The paper provides a general meta-philosophical groundwork for the theoretical and applied normative evaluation of information and digital information specifically in relation to the good life. The overall aim of the paper is to address the question of how Information Ethics and computer ethics more generally can be expanded to include more centrally the issue of how and to what extent information relates and contributes to the quality of life or the good life, for individuals and for society. To answer that question, the paper explores and provides by way of a theoretical groundwork for further research, the notion of wisdom understood as a type of meta-knowledge and a type 
of meta-virtue that can enable one to both know in principle what a good life is and how to go about applying that knowledge in living such a life in practice. This answer is based on the main argument presented in the paper that the notion of wisdom understood as a composite epistemological, axiological and eudemonic concept provides the essential conceptual link between information on the one hand and the good life on the other. If as we are told this is the Age of Information, both the theoretical examination of the question of how information relates to the good life and the provision of an adequate answer to that question are essential for developing a deeper understanding of how to evaluate the theoretical implications and practical ramifications of information for the good life, for individuals and societies generally.

In offering this theoretical groundwork the paper, due to constraints of space, will not provide a detailed examination and evaluation of specific normative issues, which arise in the production, dissemination and use of digital information in particular contexts and instances. It will, however, provide in section "The application of wisdom for the normative evaluation of digital information in relation to the concept of a good life" a methodological approach of how different types of some major practical manifestations of digital information can be evaluated using the meta-theoretical framework proposed in this paper.

The paper comprises three main inter-related parts. Section "A universal model for evaluating the normative quality of digital information" provides a summary of an argument whose primary aim is to demonstrate a metaphilosophical model, the Dual Obligation Information Theory (DOIT) (Spence 2009a) to be used in the analysis and evaluation of digital information in terms of its inherent normative categories. Those categories are the epistemological and the ethical. As this argument has been analyzed and demonstrated in much detail in an earlier paper (Spence 2009b), section "A universal model for evaluating the normative quality of digital information" of the paper will merely provide a summary of that argument in order to initiate, motivate and advance the main argument of this paper, which is that the notion of wisdom as at once a meta-epistemological, meta-axiological and metaeudemonic concept provides the essential theoretical term that conceptually links information to the good life. This forms the overall objective of section "Information, knowledge and wisdom" of the paper, which is, the examination and evaluation of the theoretical and practical relationship between information, knowledge and wisdom, using as its point of departure the meta-philosophical analysis provided by the Dual Obligation Information Theory (DOIT) of section "A universal model for evaluating the normative quality of digital information".
Of central importance, section "Information, knowledge and wisdom", which provides the focal direction of the paper, offers an innovative approach in evaluating information and its relation to the good life, through the concept of wisdom. Wisdom understood as a type of meta-information or meta-knowledge, which comprises also essential, ethical, axiological and eudemonic features, provides a direct conceptual and practical link between the concepts of information, knowledge and the good life. More generally, it provides a direct link between information ethics and the good life. As such, the concept of wisdom allows for a direct evaluation of information in relation to a conception of a good life. Following on from sections "A universal model for evaluating the normative quality of digital information", and "Information, knowledge and wisdom"), the section, "The application of wisdom for the normative evaluation of digital information in relation to the concept of a good life" provides a theoretical rationale to demonstrate the important and relevant role that wisdom plays in the specific evaluation of digital information. To that end, a methodological approach is used to show how some different general types of practical manifestations of digital information can be normatively evaluated in relation to a conception of a good life through the application of the concept of wisdom as developed in section "Information, knowledge and wisdom".

However, before proceeding, we should first address the general question of why wisdom is at all relevant to the relationship between information and a good life? Why not proceed directly to examining the role that information itself plays in the good life? Why do we need the intermediary concept of wisdom? The answer is fairly simple and straightforward. Wisdom, and to repeat what was said earlier, being at once a meta- axiological, meta-epistemological and meta-eudemonic term provides an immediate and direct conceptual link between information (an epistemological term) and the good life (an axiological-eudemonic term). As a meta-epistemological term, wisdom as a form of meta-knowledge is capable of providing an individual with the necessary reflective knowledge and understanding for evaluating and applying first-order knowledge, which includes both knowledge that (theoretical knowledge) and knowledge how (practical knowledge), in making judgments to reach decisions that concern and impact on different aspects of a person's life (general aspects such as capacities, constraints and circumstances). The ultimate purpose of which is to assist and guide that person in living a good life. For what would be the point of choosing and leading a life that was not at least in principle capable of providing a good life or at least, a life that is overall better with wisdom than without it?

A basic pre-supposition of this paper is that the presence of wisdom is, all things being equal, a better guide for a 
good life than its absence or its semantic and conceptual opposite, folly. ${ }^{1}$ The notion of wisdom that informs the discussion of this paper and is developed in greater detail in section "Information, knowledge and wisdom" is conceived as forming a continuum comprising degrees of wisdom. At the two extreme conceptual ends of the continuum we have wisdom ( $\operatorname{good}=1)$ and folly $(\mathrm{bad}=0)$. Most people, I speculate, probably fall somewhere in the middle-they are neither wise nor foolish.

Yet another reason why wisdom is relevant to an enquiry concerning the role that information plays in a good life is that some of the issues with regard to the use of digital information qua good life relate not to moral or immoral conduct by an individual towards others but to the prudentially appropriate or inappropriate conduct of the individual in relation to themselves. For example, if an individual posts compromising pictures of themselves on Facebook or Myspace that causes no harm to anyone else but themselves, then the matter is not one of ethics but one of wisdom or at least prudence ${ }^{2}$ - how wise or prudent was the individual to do so, if the outcome of their unwise or foolish behavior in public cyberspace turned out to be harmful to themselves in some way-say, as a result of their unwise or foolish conduct that individual was fired from a job that they enjoyed.

In sum, the paper will seek to show that although related, wisdom is conceptually distinct and conceptually different from both information and knowledge in a crucial way. For wisdom unlike information and first-order knowledge provides a person with understanding concerning the techne biou or craftsmanship of living in the sense of knowing how to evaluate and apply relevant information or knowledge for the attainment of a good life and in addition, an appreciation in knowing why such a life constitutes a good life. This is similar to the notion of wisdom defended by Sharon Ryan who in her article "What is Wisdom?" concludes that an accurate answer to that question is that " $\mathrm{S}$ is wise if $\mathrm{S}$ knows, in general, how

\footnotetext{
${ }^{1}$ Erasmus of course in Praise of Folly makes a case, albeit an ironic and satiric one, that Folly is in fact a better guide than Wisdom for having a good life in this world. On the serious side, Erasmus, however, goes on to suggest in the last section of In Praise of Folly that since only God is capable of wisdom and human-beings only capable of folly we should submit ourselves to the will and guidance of God. Being primarily a secular examination of the role of wisdom in a good life, this paper will not, however, pursue that theological line of inquiry interesting though it might be.

2 The term prudence used throughout this paper refers to the virtue of prudence conceived as an enabling disposition or trait of character that has the tendency of preventing an individual of engaging in conduct that is likely to cause them harm. That is, conduct unbecoming of a virtuous person. Unlike the term instrumental rationality, which is a non-moral term and refers to the non-moral self-interest of an individual, prudence by contrast refers to the virtuous and hence moral self-interest of an individual person.
}

to live well and if $S$ has a general appreciation of the true value of living well (Ryan 1999, pp. 119-39). Ryan's views on wisdom will be discussed in more detail in section "Information, knowledge and wisdom" of the paper.

In a nutshell, the argument I advance in this paper for the evaluation of information (including digital information) in relation to the good life, through the intermediary concept of wisdom, is as follows ${ }^{3}$ :

(1) The dissemination of information as a process of communication entails a number of general epistemological and ethical values and norms that are necessary and universal for all informational agents in virtue of the inherent normative structure of Information AND the inherent normative structure of Action. Informational Action therefore has a dual inherent normative structure that commits all informational agents to general epistemological and ethical values and norms. This is the conclusion of the argument from the Dual Information Obligation Theory addressed in section "A universal model for evaluating the normative quality of digital information".

(2) Moreover, wisdom as a form of meta-knowledge about what a good life is, the value of such a life, and how to actively pursue and realize it, is a reflective meta-virtue whose possession enables the evaluation and application of first-order knowledge in the promotion of the good life for its attainment, both for an individual, and society generally.

(3) Since wisdom requires information and knowledge oriented towards the realization of the good life, and since the acquisition and communication of such knowledge entails epistemic and ethical norms, as well as axiological and eudemonic values that relate to the good life, wisdom is therefore central and crucial to the evaluation of information, including digital information, and its relation to the good life.

Hence, the normative structure of informational action as discussed in section "A universal model for evaluating the normative quality of digital information" is shown to have a common conceptual connection with wisdom with regard to the promotion and attainment of a good life, as discussed in sections, "Information, knowledge and wisdom" and "The application of wisdom for the normative evaluation of digital information in relation to the concept of a good life" of this paper. Moreover, the argument as outlined above and discussed at length in what follows, demonstrates that Information Ethics by implication and by rational extension becomes the Ethics of Wisdom.

\footnotetext{
${ }^{3}$ I owe with gratitude the initial prompting and basis for the formulation of this summation of my argument to one of the reviewers of this paper.
} 
A universal model for evaluating the normative quality of digital information ${ }^{4}$

The object of this part of the paper is to describe and demonstrate in summary a meta-theoretical framework for the normative evaluation of digital information in terms of its inherent epistemological and ethical categories. The primary aim for doing so is to demonstrate in the first instance the conceptual relationship between information and knowledge and the epistemological and ethical commitments to which information understood as a type of knowledge gives rise. As mentioned earlier, the argument for the inherent normative structure of information as a process of communicative action has been examined and demonstrated at length in a previous publication devoted exclusively to that topic (Spence 2009a). In this part of the paper my concern is simply to provide a summary of that argument sufficient for establishing an initial theoretical standpoint from which to further motivate and develop the normative relationship between information, knowledge, wisdom and the good life that forms the main topic of discussion in section "Information, knowledge and wisdom". The demonstration of that normative relationship, at once epistemological, axiological and eudemonic, will establish and demonstrate a direct normative link between information and the good life. Its purpose is to provide a methodological approach in terms of a wisdom-theoretic model for the normative evaluation of that relationship and its implications and ramifications for individuals and societies generally.

The inherent normative structure of information and knowledge

In describing the Dual Obligation Information Theory (DOIT) used for the normative evaluation of information in terms of its inherent epistemological and ethical categories the paper will employ an epistemological account of semantic information based on a minimal nuclear definition of information (Dretske 1999, p. 45). Following Floridi information is defined as "well-formed meaningful data that is truthful" (2005) and following Dretske information is defined as "an objective commodity capable of yielding knowledge" and knowledge, in turn, is defined as "information caused belief" (Dretske 1999, pp. 44-45 and 86).

The reference to both Floridi's and Dretske's notions of information in this paper is not intended for making any critical theoretical comparisons between those two accounts of information (which entirely lies beyond the

\footnotetext{
4 This model is presented in greater detail in Spence (2009a), A Universal Model for the Normative Evaluation of Internet Information., Ethics and Information Technology, 11 (4).
}

scope of this paper). It is rather intended for highlighting the one essential element that those accounts have in common, namely, that what is necessary for both information and knowledge is truth. For information without truth is not strictly speaking information but either misinformation (the unintentional dissemination of well-formed and meaningful false data) or disinformation (the intentional dissemination of false "information").

Using the minimal account of information described above, we can now develop an inherent normative account of information, which demonstrates and describes the generic epistemological and ethical commitments that necessarily arise in the dissemination of semantic information, specifically as a process of communication.

Briefly, the argument is as follows (Spence 2009a): Insofar as information is a type of knowledge (it must be capable of yielding knowledge, one must be able to learn from it) it must comply with the epistemological conditions of knowledge, specifically, that of truth. And insofar as the dissemination of information is based on the justified and rightful expectation among its disseminators and especially its users that such information should meet the minimal condition of truth, then the disseminators of information are committed to certain widely recognized and accepted epistemological criteria. Those epistemic criteria will in the main comprise the objectivity as well as the independence, reliability, accuracy and trustworthiness of the sources that generate the information. The epistemology of information, in turn, commits its disseminators to certain ethical principles, values and virtues, such as honesty, sincerity, truthfulness, trustworthiness and reliability (also epistemological values), and fairness, including justice, which requires the equal distribution of the informational goods to all citizens. Thus in terms of its dissemination, as a process of communication, information has an intrinsic normative structure that commits everyone involved in its creation, production, search, communication, consumption and multiple other uses to epistemological and ethical norms. These norms being intrinsic to the normative structure of information with regard to all its disseminating modes are rationally unavoidable and thus not merely optional.

Information and universal rights

The object of the following associated argument to the one above (Spence 2009a) is to show that in addition of committing its disseminators to unavoidable epistemological and ethical standards by virtue of its own inherent normative structure in terms of truth, information as a process of communication commits its disseminators to respect for peoples' rights to freedom and wellbeing. This is so by virtue of the inherent normative structure of action and specifically informational action, due to its essential 
features of freedom and wellbeing (Spence 2006; Gewirth 1978). ${ }^{5}$ Insofar as the communication of information constitutes a type of informational action, information as a process and product of communication must not be disseminated in ways that violate peoples' fundamental rights to freedom and wellbeing (generic rights), individually or collectively, or undermine their capacity for self-fulfilment (negative rights).

In addition, information must as far as possible be disseminated in ways that secure and promote peoples' generic rights and capacity for self-fulfilment (positive rights) when those rights cannot be secured or promoted by the individuals themselves and can be so secured and promoted at no comparable cost to its disseminators. ${ }^{6}$ Due to constrains of space, I will not attempt to provide a justification for Alan Gewirth's argument for the Principle of Generic Consistency (PGC) on which his derivation of rights is based, as this is well beyond the scope and limits of this paper. $^{7}$

In conclusion of sections "The inherent normative structure of information and knowledge" and ("Information and universal rights"), the Dual Obligation Information Theory (DOIT) demonstrates the doubly-normative structure of informational action, to which all informational agents, including the media (both corporate and new media) are committed by universal necessity. It does so by firstly disclosing the inherent normative structure of information as a process of communication and secondly by disclosing the inherent normative structure of communication as a type of informational action. Hence, information as a process of communication can generally be epistemologically and ethically evaluated internally by reference to its inherent normative structure. That structure commits its disseminators, to ethical and epistemological norms. This is especially true of professional communicators (Journalists and PR Consultants, for example,

\footnotetext{
5 Alan Gewirth's main thesis in Reason and Morality (1978) is that every rational agent, in virtue of engaging in action, is logically committed to accept a supreme moral principle, the Principle of Generic Consistency that commits every agent to respect the rights of freedom and wellbeing of all other agents including their own. The basis of his thesis is found in his doctrine that action has an inherent normative structure whose necessary features are freedom and wellbeing, and because of this structure every rational agent, just in virtue of being an agent, is committed to certain necessary prudential and moral constraints and in particular respect for all agents' rights to freedom and wellbeing.

${ }^{6}$ Gewirth. The Community of Rights. Chicago: University of Chicago Press, 1996, and E. Spence. Ethics Within Reason: A NeoGewirthian Approach. Lanham: Lexington Books (a division of Rowman and Littlefield), 2006.

7 For a detailed exposition and analysis of Gewirth's argument for the PGC see E. Spence. Ethics Within Reason: A Neo-Gewirthian Approach. Lanham: Lexington Books (a division of Rowman and Littlefield), 2006.
}

on-line and off-line). Expressive Information can also be evaluated in this way. For example, identity theft on the Internet is morally wrong both because it is untruthful and because it can cause harm (violates the individual's rights whose identity has been stolen).

\section{Information, knowledge and wisdom ${ }^{8}$}

Information and the good informational agent

Although the Dual Obligation Information Theory (DOIT) provides a meta-theoretical model for evaluating information in terms of epistemological and ethical categories, it does not, at least not directly, provide a method for the evaluation of information in terms of a normative axiological category in relation to the notion of a good life. DOIT, however, does initially provide a method for an indirect axiological evaluation of information through the notion of a good person and in particular a good informational person or good informational agent. Consider the following argument. I will refer to it as the Argument from the Goodness of Informational Agents (GIA): (a) Since DOIT requires all agents, including informational agents, to act epistemically and ethically (or at least acknowledge that they ought to act epistemically and ethically) in respecting the rights to freedom and wellbeing of other informational agents including their own; and (b) insofar as virtues of character such as the cardinal virtues of justice, courage, moderation and prudence; the epistemic virtues of communication such as honesty, sincerity, truthfulness, trustworthiness and reliability; as well as the Humean moral sentiments, such as sympathy (positive) and remorse (negative), can be conceived as enabling dispositions that allow agents generally and informational agents specifically to act epistemically and ethically in compliance with DOIT; then (c) the inculcation of those virtues and cultivation of those sentiments are also rationally required, at least prudentially (Spence 2006, chapter 5, 2009a). For if one recognises the value of acting epistemically and ethically as an informational agent as well as recognises the value of the virtues and moral sentiments as enabling dispositions in achieving that objective, then one ought to also rationally recognise and acknowledge the value of

\footnotetext{
${ }^{8}$ Surprisingly, very little has been written on this relationship in the philosophical literature, specifically with regard to information ethics. The main sources I will refer to in this part of the paper, but not exclusively, are Maxwell (2007), Tiberius (2008), Vitek and Jackson (2008), Varelius (2004), Kvanvig (2003), Finnis (1980, 1983), Ryan (2007, 1999), Kekes (1995); and generally the writings of Plato (Apology), Aristotle (Nichomachean Ethics) and the Hellenistic Philosophers (Epicureans, Sceptics and Stoics) - for a discussion of those see (Spence 2006, Ch. 10).
} 
inculcating those virtues and moral sentiments in one's character. At the very least, given that rational recognition and acknowledgement, it would be prudent for one to do so.

\section{Information and the good life}

Having initially and indirectly provided a conceptual link between information and the notion of a good informational agent above, on the basis of the Argument from the Goodness of Informational Agents (GIA), it is now time to examine the relationship between information and the notion of a good life more directly. At first approximation, we can say quite reasonably that a good life generally is one that is at least minimally capable of enabling a person to attain self-fulfillment, well-being, happiness or eudemonia. I will for methodological convenience use the term eudemonia ${ }^{9}$ to include and refer to all those concepts collectively whilst maintaining the original meaning for that term as intended by the ancient Greek philosophers, including Plato, Aristotle, and the Hellenistic philosophers and in particular the Stoics and the Epicureans (see Spence 2006, Ch. 10). Although those philosophers might have explained the notion and attainment of eudemonia in different ways they all at least agreed that the virtues were essential for the attainment of a eudemonic or a flourishing life and moreover the virtues were constitutive of such a life. For insofar as eudemonia is the ultimate object in life as Aristotle claimed, it is difficult to conceive a life that was not at least capable of leading to the attainment of eudemonia, as good-what would it be good for if it were incapable of at least in principle enabling one to realize one's ultimate objective in life?

Furthermore we can say initially and pending further discussion in section "Information, knowledge and wisdom and their relationship to the good life" that a good life for an informational agent is, in turn, capable of enabling the attainment of eudemonia for that informational agent in the infosphere (Floridi and Sanders 2002) if it accords with the minimal normative epistemological and ethical requirements mandated by the Dual Obligation Information Theory (DOIT).As we saw earlier those requirements can more successfully be complied with through the inculcation of

\footnotetext{
${ }^{9}$ For the purposes of this paper I will use the notions of eudemonia and eudemonic pluralistically as being potentially compatible with various different theories of the good life, including hedonistic, desire-satisfaction and objective-list theories among others. Simply put, the notion of a good life used in this paper is a good life that is in principle capable of leading to the attainment of eudemonia. As such, any theory of a good life capable of leading to eudemonia can at least in theory and upon further demonstration be considered a eudemonic life. My own theoretical preference is a eudemonic life that includes the virtues but that need not exclude other theories capable of also leading to the attainment of eudemonia.
}

the virtues and the moral sentiments, in accordance with an indirect application of DOIT on the basis of the Argument from the Goodness of Informational Agents (GIA). That is to say, a good life capable of leading to or at least contributing to the eudemonia of informational agents or informational beings is more likely to be realizable if one is a good informational agent or a good informational being - that is, if one has a good character comprising both the moral virtues and moral sentiments. And by being good one is also more likely to comply with the mandatory requirements of DOIT in respecting the rights (both ethical and epistemological) of other informational agents including one's own.

Information, knowledge and wisdom and their relationship to the good life

This is the focal and main part of the paper whose aim is the examination and evaluation of the relationship between the concepts of information, knowledge and wisdom. Approximately and pending further discussion below, wisdom in this paper is conceived as a type of metaknowledge that is used in the evaluation and application of information and knowledge to make right judgments in reaching appropriate decisions that are of value and good for us in our lives personally (prudentially and eudemonically good) and that are of value and good for others in their lives (ethically good) for the ultimate attainment of a good life resulting in eudemonia. The overall objective of this line of enquiry is to further determine what the relationship between information and the good life is and to what degree, if any, information can in principle contribute to a good life.

In section "Information and the good life" we saw how information can initially be indirectly related to the notion of a good life though the axiological notion of a good agent and specifically a good informational agent. In this part of the paper, we shall examine more closely how information can be directly related to the notion of a good life via the concept of wisdom: if wisdom is a primary and essential condition for an individual in (a) determining what a good life is or ought to be (meta-knowledge- that and metaknowledge-why) and (b) a primary and essential condition in providing us with guidance and direction, both as individuals and societies generally, of how to live such good lives and (c) moreover, wisdom, as a reflective meta-virtue is an enabling disposition of character that practically enables us to live such good lives for the attainment of eudemonia (meta-knowledge-how), to what extent and in what ways, if any, does information contribute to wisdom and by extension to the good life?

The paper posits that one direct way of evaluating the value of information and its relation to a good life generally 
(its overall axiological goodness) is by determining the degree to which it contributes or is capable of contributing to the attainment of a good life epistemologically (its capacity to yield knowledge), ethically (its ability to contribute to the moral good of others both negatively by causing no unjustified harm to others, and positively by causing positive good for others) and eudemonically (its capacity to contribute to both the conception and the attainment of a good life). The paper will show that in order to achieve that theoretical objective the notion of wisdom is essentially required.

Analyzing information through the application of the concept of meta-knowledge (knowledge-that, knowledgehow and knowledge-why) of what is good or evil for us and others-how it contributes or is capable of contributing to a good life for us and others for the attainment of eudemonia-is what the paper will initially postulate as Wisdom. In sum, if a good life should at least be capable of leading to self-fulfilment or eudemonia (otherwise what is it good for?), especially self-fulfilment as capacity-fulfilment (making the best of oneself as a human-being-Gewirth 1998) ${ }^{10}$ then wisdom (understood as a type of metaknowledge, the acquisition of which enables one to create, communicate and use information so as to render oneself and others, whenever possible, capable of achieving selffulfilment and eudemonia) is a necessary condition for a good life.

An important qualification to the claim made in this paper that wisdom is a necessary condition for a good life is that such a life is conceived eudemonically. For the notion of wisdom developed in this paper and applied in evaluating the axiological goodness of information is itself a eudemonic conception of wisdom. However, such a eudemonic notion of wisdom is not unlike our commonsense and pre-theoretical understanding of wisdom, namely, an overarching reflective capacity the possession of which allows one to lead a good life and moreover enables one to guide others in leading fulfilling and good lives. This eudemonic notion of wisdom is akin to the notions of wisdom defended by philosophers such as Plato, Aristotle, the Epicureans and the Stoics, and later Kant and Gewirth $^{11}$ who although postulated and defended somewhat different notions of the good life, can nevertheless collectively be thought of as offering eudemonic accounts of the good life.

\footnotetext{
${ }^{10}$ In Spence 2006, Chapter 10, I demonstrate how Gewirth's notion of self-fulfillment as capacity-fulfillment, is conceptually similar to the Stoic notion of eudemonia.

11 In Spence (2006) Ethics Within Reason: A Neo-Gewirthian Approach, Chapter 10, I argue for a Neo-Stoic interpretation of Gewirth's notion of self-fulfilment in terms of the Greek notion of eudemonia.
}

It can be said that a common denominator for all the above cited eudemonic accounts of wisdom is their subordination of the concepts of pleasure and desire to that of virtue. The essential link between pleasure and desire on the one hand and virtue on the other might be weaker in the case of the Epicureans and stronger in the case of the Stoics but whatever the strength of that relationship might be, the link between pleasure, desire and virtue is an essential characteristic of traditional eudemonic conceptions of a good life and also eudemonic conceptions of wisdom. Moreover, as mentioned above, another essential characteristic of a eudemonic conception of a good life is that such a life is capable of resulting in the attainment of eudemonia. As such, the term eudemonic understood in this very general sense is compatible with a number of other theories of the good life which can be shown to be capable of leading to the attainment of eudemonia. This is in keeping with the Eudemonist Axiom, the view that "happiness is desired by all human beings as the ultimate end or telos of all rational action".

Importantly, the relationship between wisdom and a good life proposed in this paper under a eudemonic conception of a good life is reflexive. For wisdom guides one to the choice of a eudemonic conception of a good life and the pursuit of such a life, and a eudemonic conception of a good life, in turn, guides and motivates one to the acquisition of wisdom as an enabling disposition, in the form of an overarching reflective virtue, which is necessary for the attainment of a eudemonic life. This should not surprise us. For although wisdom acts initially instrumentally, as a necessary enabling virtuous disposition for the attainment of a eudemonic life, once attained, a eudemonic life becomes inseparable from the state of wisdom that enabled its attainment. This reflexivity between eudemonia and wisdom allows us then to say that a wise person is generally a eudemonic person and a eudemonic person is generally a wise person. However, I don't wish to exclude the logical possibility that one could be wise but unhappy although pragmatically, given our common understanding of wisdom, that would be an odd thing to say and in practice I think, an unusual occurrence.

What is wisdom?

Having examined in some detail what information and knowledge are and what the relationship is that exists between them (by way of an examination of the essential property that characterises both, namely, the property of truth) it is now time to turn our attention to the notion of wisdom so as to explore further the conceptual relationship that holds between information, wisdom and a good life.

According to Nicholas Maxwell, 
The central task of inquiry is to devote reason to the enhancement of wisdom - wisdom being understood here as the desire, the active endeavour, and the capacity to discover and achieve what is desirable and of value in life, both for oneself and for others. Wisdom includes knowledge and understanding but goes beyond them in also including: the desire and active striving for what is of value, the ability to see what is of value, actually and potentially, in the circumstances of life, the ability to experience value, the capacity to help solve those problems of living that arise in connection with attempts to realize what is of value, the capacity to use and develop knowledge, technology and understanding as needed for the realization of value. Wisdom, like knowledge, can be conceived of, not only in personal terms, but also in institutional or social terms. We can thus interpret the philosophy of wisdom as asserting: the basic task of rational inquiry is to help us develop wiser ways of living, wiser institutions, customs and social relations, a wiser world $(2007,79)$.

What is of interest in Maxwell's quoted passage for our present purposes is the relationship he draws between the concepts of reason, knowledge, understanding, and the desire, capacity, and active endeavour for the achievement (or as in my case attainment) of what is of value in life, for oneself and others. With the exception of understanding, for which I will have more to say in what follows, the other concepts to which Maxwell draws attention seems to anticipate and reflect both explicitly and implicitly, the concepts included in my own normative analysis of information and knowledge, in terms of their epistemological, ethical, and axiological dimensions. The basis of that analysis is the meta-theoretical framework comprising the Dual Obligation Information Theory and the Argument from the Goodness of Informational Agents.

\section{Four theories of wisdom}

In an article in the Stanford Encyclopedia of Philosophy, Ryan (2007) identifies at least four different theories of wisdom: (A) Wisdom as Epistemic Humility, which she attributes to Socrates in Plato's Apology (20e-23c). There Socrates expresses puzzlement concerning the oracle of Delphi's pronouncement that he is the "wisest of men" and declares that his knowledge extends only as far as his knowledge of his own ignorance, the prototype case of epistemic humility (B) Wisdom as Epistemic Accuracy, for which Ryan provides two versions to the effect that (B1) $S$ is wise iff for all $p$, ( $S$ believes $S$ knows $p$ iff $S$ knows $p$.) (EA1) or the weaker version (B2) $S$ is wise iff for all $p$, ( $S$ believes $S$ knows p iff $S$ 's belief in $p$ is highly justified.)
(EA2); (C) Wisdom as Knowledge: the view that knowledge is at least a necessary condition of wisdom. Ryan identifies several philosophers who hold some version of (C) including Aristotle (1941, VI, Ch. 7), Descartes, R. (1979, pp. 201-302).), Garrett (1996), Kekes (1983), Lehrer et al. (1996), Nicholas Maxwell (2007), Robert Nozick (1989), Plato (1978), and Ryan (1996, 1999). According to Ryan, all these philosophers "have theories of wisdom that require a wise person to have some knowledge of some sort" and what's more, "all these views maintain that wise people know what is important" (2007). Overall, these theories differ according to Ryan "over what it is that the wise person must know and whether there is any action that is required for wisdom" (2007).

In order to further differentiate different notions of wisdom that fall under the broad category of "wisdom as knowledge" Ryan refers to Aristotle who held two main theories of wisdom, Sophia or Theoretical Wisdom and Phronesis or Practical Wisdom. Theoretical wisdom according to Aristotle is "scientific knowledge, combined with intuitive reason, of the things that are highest by nature (Ryan 2007 quoting Aristotle in Nichomachean Ethics, VI, 1141b). On that basis, Ryan interprets Aristotle's notion of theoretical wisdom as the following view: (C1) Wisdom as extensive factual knowledge (WFK) which in effect amounts to " $S$ is wise iff $S$ has extensive factual knowledge about science, history, philosophy, literature, music, etc." (Ryan 2007). Ryan finds this notion of wisdom implausible for as she correctly observes "some of the most knowledgeable people are not wise" (Ryan 2007). Ryan maintains that Aristotle's notion of phronesis or practical wisdom is a more reasonable theory to hold. According to Aristotle,

Now it is thought to be the mark of a man of practical wisdom to be able to deliberate well about what is good and expedient for himself, not in some particular respect, e.g. about what sorts of things conduce to health or strength, but about what sorts of things conduce to the good life in general (Nichomachean Ethics, VI, 1140a01140b).

Ryan concludes that "for Aristotle, practical wisdom requires knowing, in general, how to live well". She goes on to say that although many philosophers are in agreement with Aristotle on this point they would not agree with Aristotle "that theoretical wisdom is one kind of wisdom and practical wisdom another. Wisdom, in general," Ryan concludes, "requires practical wisdom" (2007). I agree.

In support of this general notion of practical wisdom Ryan cites Robert Nozick who claims that "Wisdom is what you need to understand in order to live well and cope with the central problems and avoid the dangers in the 
predicaments human beings find themselves in" (Nozick 1989 , p. 267). She also cites John Kekes, whose view is that "what a wise man knows, therefore, is how to construct a pattern that, given the human situation, is likely to lead to a good life (Kekes 1983, p. 280). Ryan defines this type of general practical wisdom as (C2) Wisdom as Knowing How to Live Well (KLW): " $S$ is wise iff $S$ knows how to live well", which according to Ryan captures on the whole Aristotle's concept of practical wisdom as well as the views held by Nozick et al. (2007).

The final theory of wisdom that Ryan considers is Wisdom as Knowledge and Action, which she specifically defines as Wisdom as Knowing How To, and Succeeding at, Living Well (KLS), which in effect amounts to: $S$ is wise iff (i) $S$ knows how to live well, and (ii) $S$ is successful at living well (2007). According to Ryan the "idea of the success condition [condition (ii) in KLS] is that one puts one's knowledge into practice". She goes on to attribute a view broadly along the lines of (KLS) to Aristotle (his notion of practical wisdom), as well as to Kekes and Nozick. Ryan herself rejects this theory based on criticisms she raises in (Ryan 1999) but her main criticism with which I concur is that (KLS) seems to leave out the factual knowledge required by the theory of wisdom as extensive factual knowledge (WFK).

In agreement with Ryan I also claim that some factual knowledge of the world (but not necessarily extensive) adequate for enabling a person to make their way in the world and have a good life, is necessary for wisdom. This consideration introduces an important distinction when enquiring into the conceptual connection between knowledge and wisdom: the distinction between knowledge for wisdom and knowledge as wisdom. Although related the two are quite different and their difference highlights an important and crucial distinction between knowledge and wisdom.

No doubt some general knowledge about the world acquired on the basis of reliable and veridical information that causes it and sustains it (Dretske 1999) is necessary for wisdom. This is in keeping with the notion of Socratic ignorance, roughly understood here as having knowledge of one's ignorance (being aware of one's ignorance and humbly acknowledging one's lack of knowledge). For Socratic ignorance prompts and motivates one to acquire the knowledge of which one is ignorant (knowledge understood here as some minimal general knowledge about some basic aspects of the world, e.g., history, geography, science, mathematics, literature, art, etc.). Socratic ignorance as a special type of knowledge accords with Ryan's theory of wisdom as epistemic humility, which was examined earlier. By contrast, those who claim to know what they lack knowledge of, are not in a position to be motivated to acquire the knowledge they lack; and moreover, the knowledge that is at least in a minimal and general sense partly necessary for the acquisition of wisdom and by extension, the attainment of a good life and eudemonia.

Thus at a minimum, and bracketing the possibility that "holy fools" though totally ignorant of facts about the world are nevertheless in some sense "wise", some minimal and general knowledge about the world is instrumentally and prudentially necessary for the acquisition of wisdom. At least at a minimum, an attitude of Socratic ignorance $^{12}$ might be necessary for the acquisition of wisdom. For the Socratic elenchus can be applied as a method for acquiring the knowledge one lacks, through first recognizing and acknowledging one's ignorance, and then being motivated to gradually acquire the knowledge of which one is ignorant, through critical enquiry and further investigation. According to John Kekes, "the elenchus enables its practitioners to progress from a special kind of ignorance - foolishness - to a special kind of knowledgemoral wisdom" (1995, p. 39).

We can therefore say that the acquisition of such general minimal knowledge about the world or an attitude of Socratic ignorance when we lack such knowledge is instrumental to the acquisition of wisdom because it provides at least part of the necessary means, that is, the capacity for the acquisition of wisdom. Moreover, the acquisition of such minimal and general knowledge of the world or in its absence, an adoption of an attitude of Socratic ignorance, is prudential to the acquisition of wisdom. Insofar as we consider the acquisition of wisdom desirable, valuable and essential for the attainment of a good life, we should (normatively) inculcate in ourselves the virtue of learning: the desire and active pursuit of the acquisition of at least a minimal and general knowledge about the world. Hence, some minimal and general knowledge about the world is necessary for wisdom.

Where I disagree with Ryan with regard to her formulation for (KLS), however, is her claim that one's practical knowledge in living well when put into practice should necessarily succeed in one's living well. After all, circumstance beyond one's control and the "arrows of outrageous fortune" might frustrate one's best efforts in succeeding to live well. My re-formulation of KLS is a modification of Ryan's fourth theory of wisdom as knowledge and action to, Wisdom as Knowing How to Live Well and Successfully Applying that Knowledge in Living Well (KLSA), which amount to $S$ is wise iff (i) $S$ knows how to live well, and (ii) $S$ successfully applies that knowledge at living well. According to my re-formulation

\footnotetext{
${ }^{12}$ For a detailed discussion of the Socratic elenchus and Socratic wisdom see Benson (2000) Socratic Wisdom: The Model of Knowledge in Plato's Early Dialogues, Oxford University Press.
} 
of KLS as KLSA, it is actual successful application of the knowledge of how to live well rather than actually succeeding in living well that is important. A subtle difference perhaps, but I think an important one. For my re-formulation of KLS in terms of KLSA avoids the problem of rendering wisdom a hostage to fortune. One can be wise even though, because of circumstances beyond one's control, one fails to succeed in living well. It is sufficient that one both knows how to live well and one successfully applies that knowledge of how to live well, regardless of one's actual success or failure in living well.

In addition, along with Aristotle, I also wish to claim that being a good person is a necessary, if not sufficient, condition for being wise. For Aristotle claims, "Therefore it is evident that it is impossible to be practically wise without being good" (Nichomachean Ethics, VI 1144a). You will recall that the goodness of the agent and specifically the informational agent in terms of the possession of a virtuous character, was discussed in ("Information and the good life") on the basis of the Argument from the Goodness of Informational Agents (GIA). (See also Spence 2006, Ch. 10).

John Kekes seems to also have the view that a virtuous character is an essential characteristic of the wise person. In the opening sentence of his book Moral Wisdom and Good Lives (1995, p. ix) Kekes tells us that "moral wisdom is a virtue-the virtue of reflection". A more detailed characterisation of moral wisdom by Kekes, is that

Moral wisdom is the capacity [a psychological capacity] to judge rightly what should be done in particular situations to make life better...Because this human psychological capacity, once developed, is likely to be lasting and important, it can be identified as a character trait....We can say, therefore, that people have moral wisdom if they regularly and predictably act wisely in the appropriate situations and if so acting is an enduring pattern in their lives... Whether an action is morally wise depends also on what the agents bring to the judgements they make, such as their particular conception of what would make life better. An action being morally wise depends therefore not just on the nature of the action and the situation, but also on the agent, and this invalidates generalisations of moral wisdom which ignore the character and beliefs of the agents. (1995, $5-7)$.

According to Kekes, moral wisdom is a second order virtue whose primary concern,

[Is] the development of our character [emphasis added] in a desirable direction by strengthening or weakening some of our dispositions. First-order virtues guide our actions in view of what we think of a good life; second-order virtues guide our actions with a view of developing the kind of character that reflects a reasonable conception of a good life $(1995,9)$.

\section{The psychology of wisdom: the Berlin wisdom paradigm}

Finally, it is worth mentioning a psychological theory of wisdom that runs parallel to the philosophical theories of wisdom discussed above. This is the theory of wisdom postulated by Paul Baltes and his research associates from the Max Planck Institute for Human Development in Berlin. The theory known as the Berlin Wisdom Paradigm views wisdom as a kind of expertise in the matters of human life (Baltes et al. 2002, Baltes and Smith 1990 as referred to by Banicki 2009). According to Banicki (2009), wisdom as knowledge is viewed in the theory of the Berlin Wisdom Paradigm as.

"Integrative, Holistic and Balanced" (Baltes et al. 2002, p.342) and, as such, is intended to involve cognitive, social, personal, motivational, emotional and behavioral elements. Furthermore, the knowledge in question is again strictly connected with judgment and action. Accordingly, Baltes and Smith (1990, p. 95) characterize wisdom as "expert knowledge involving good judgment and advice" and associate it with three main tasks in life: planning (future), review (past) and management (present).

In a chapter from A Handbook of Wisdom: Psychological Perspectives (Sternberg and Jordan 2005, p. 115) Kunzmann and Baltes define wisdom in accordance with the Berlin Wisdom Paradigm, as a

Highly valued and outstanding expertise in dealing with fundamental, that is, existential, problems related to the meaning and conduct of life $(2005,117)$.

Or as a

Special "expertise-like" case of the pragmatics of intelligence (intellect) that includes knowledge about cognitive, motivational, and emotional aspects of adaptive functioning in a specific domain, that is, the meaning and conduct of life $(2005,115)$.

Kunzmann and Baltes go on to elaborate that the "focus of their theoretical work has been to define wisdom as an expert system in human thought and behavior that coordinates knowledge and virtue, mind and character" [emphasis added] (2005, p. 128), and that thus defined, wisdom for them "reflects both components of wisdom: intellect and character" (2005, p. 130). According to them, "wisdom differs from other human strengths in that it 
involves an orchestration of mind and virtue, intellect and character" (2005, p. 131).

It is not too much of a jump to reasonably interpret the psychological notion of the Berlin Wisdom Paradigm as expressed above by Kunzmann and Baltes as parallel and broadly in keeping with the general view of practical wisdom I argue for in this paper: namely, as knowledge of how to live well and the successful application of that knowledge in living well (KLSA). To that, however, we must also add the proviso that the knowledge in question must also include some knowledge of facts concerning the world generally and the world one experiences in specific contexts. The (KLSA) you will recall is the philosophical notion of wisdom I defended above, which is a re-formulation of Ryan's (KLS) view. Such knowledge does involve an "orchestration", as in the case of Kunzmann and Baltes' psychological notion of wisdom, of "intellect" or "cognition" (the epistemological features of wisdom in my model) and virtue and character (the ethical, axiological and eudemonic features of wisdom in my model).

\section{The application of wisdom for the normative evaluation of digital information in relation to the concept of a good life}

The story so far

The outcome of the extended argument concerning the nature of wisdom, what wisdom is, and its relationship to information and knowledge in section "Information, knowledge and wisdom" is that wisdom is a special type of meta-knowledge. Based on my re-formulation of Sharon Ryan's fourth theory of wisdom as knowledge and action (KLS), I concluded that Wisdom is Knowing How to Live Well and Successfully Applying that Knowledge in Living Well (KLSA). Insofar as the ultimate purpose of a good life is the attainment of eudemonia then wisdom, which informs the conception of a good life and directs its active pursuit for the attainment of eudemonia, is an essential condition for both the conception and the attainment of a good life. As the essential condition for both the conception and guided active pursuit and successful achievement of the good life, wisdom is therefore established as the essential conceptual connection between information and the good life and in particular information that is minimally necessary for acquiring knowledge of the things we need in order to have a good life. ${ }^{13}$ Some general knowledge about

\footnotetext{
13 I thank the reviewer of this paper for his useful suggestions in helping me to more clearly formulate this paragraph.
}

the world acquired on the basis of reliable and veridical information that causes it and sustains it (Dretske 1999) is therefore necessary for wisdom.

This, in turn, allows us to determine some of the generic implications and ramifications of information for the conception of a good life, in particular, a eudemonic conception of a good life. However, as Kekes points out, "the eudemonic conception of a good life is not to be understood as the endorsement of a particular form of life. It is rather a regulative ideal that specifies some general conditions to which all good lives must conform" [emphasis added] (Kekes 1995, p. 24). As such, the eudemonic account of a good life canvassed in this paper is broadly speaking pluralistic as it is in principle compatible with other different conceptions of a good life that meet the same necessary general conditions to which any notion of a good life must conform. For example, insofar as hedonistic, desire-satisfaction and objective list theories of the good life meet the minimal conditions for both specifying what a good life is as well as providing the enabling conditions for its practical realization, then they too can be aligned broadly to the notion of wisdom developed in this paper.

Kekes' claim cited above is insightful and very much in keeping with the eudemonic conception of a good life proposed and argued for in this paper on the basis of the Dual Obligation Information Theory (DOIT) and the Argument from the Goodness of Informational Agents (GIA). For both DOIT and GIA are intended only as a meta-theoretical regulative ideals that specify some general conditions to which all good lives (and in particular informational lives) must conform regardless of the particular contexts and contingencies of those lives.

Specifically, with regard to the creation and dissemination of information, central to those general conditions to which all good lives are bound are (a) the epistemological and ethical obligations that emanate directly from the inherent normative structure of information; (b) the universal rights to freedom and wellbeing to which all agents are entitled and which arise naturally from the inherent normative structure of informational action; and (c), the virtues of character and associated moral sentiments and values that are prudentially desirable and required as enabling general motivational dispositions for the pursuit of a good life for the ultimate attainment of eudemonia.

In sum, we can say that those general meta-conditions are encapsulated within the combined models put forth in this paper, namely, those of DOIT and Wisdom (KLSA). I will refer collectively to those theorems as the DOITWisdom model. That model moreover seems adequate for the normative evaluation of an informationally good life.

Kekes correctly claims that according to a eudemonistic conception of a good life, 
"Primary values [values that concern uniform and universal human goods and needs] may be thought of as establishing the moral limits and secondary values [values that vary across individuals in accordance with differences in cultural traditions, conceptions of a good life, and individual contingencies and circumstances] as establishing the moral possibilities that define good lives $(1995,25)$....the former define a grid [emphasis added] within which human beings must endeavour to make a good life for ourselves, while the latter provide the ways in which individuals fill in the grid" $(1995,23)$

It has been the overall objective of this paper to provide such a grid; namely, the DOIT-Wisdom model. Having discussed meta-theoretically the epistemological, ethical, axiological and eudemonic implications of information as a process of communication for individuals and society generally through the notion of wisdom in section "Information, knowledge and wisdom", I will in this final part of the paper apply the DOIT-Wisdom model to identify some of the specific implications and ramifications that the production, dissemination and communication of digital information might have for the good lives of individuals and society generally.

Why wisdom is of primary relevance to the evaluation of digital information

The DOIT-Wisdom model presented in this paper for the normative evaluation of information and its relation to the good life is a model that applies to all information whether digital or analogue regardless of whether such information is generated within the old corporate media or the new digital media. However, the exponential growth of digital information in new media in recent years, especially on the Internet, and its implications for the good life of individuals and society generally, merits special attention for at least three theoretical reasons.

There is, to begin with, a metaphysical or ontological reason: The digitalization of information has extended the natural and technological boundaries of our lives to such an extent that as Luciano Floridi correctly observes we now live in the infosphere (2002) and not just the biosphere. We have essentially become and are increasingly becoming informational beings or inforgs. As such, thousands of millions of people around the world spend a great deal of their lives, thinking, communicating, working, buying, selling, playing, socializing and generally, acting informationally, online. All these numerous and varied informational activities in the infosphere, and specifically the digital infosphere, are unavoidably related to the quality and goodness of our lives, both as individuals and collectively as societies. Hence, if wisdom is the conceptual link that normatively links information to a good life, as argued in this paper, clearly then wisdom has a direct and primary relevant role to play in the normative evaluation of digital information and its relationship to a good life in the infosphere. In particular, wisdom as phronesis or practical wisdom, a reflective virtue that enables one to exercise understanding and good judgment in one's digital informational choices and actions, with full appreciation of the value of both the means and ends of those choices and actions and their anticipated consequences for one's life, is essential for living a good life in the infosphere. ${ }^{14}$ Although not specifically writing on wisdom and its essential role in the normative evaluation of digital information and its impact on the good life, Shannon Vallor does, however, draw attention to the important role that the virtues generally play or ought to play in our online behavior (Vallor 2010).

Secondly, there is a technological reason. The digitization of information allows us countless means and ends for instantly creating and disseminating information around the globe through the Internet and other technological devices such as smart phones, for example. This unprecedented rapid and extensive dissemination of digital information can and does affect the quality of our lives both positively but also negatively. People can both benefit themselves and others through the use of digital information but they can also harm themselves and others through the unreflective misuse and abuse of information.

It is beyond the scope of this paper to discuss particular such cases in detail but the following examples might suffice to illustrate the type of unreflective and unwise misuses of information that can occur and do occur to the detriment of oneself and others: Until very recently, marketing companies worldwide could access with Facebook's permission the personal information of its 500 million plus members. Individual members on Facebook might not know that their information is being accessed and processed for marketing purposes and even if they do know they don't know who, why and how their personal information is being used both presently and in the future. "Sexting" is increasingly becoming a major social problem involving young people as the following two examples, among many other cases, illustrate: a Sydney schoolgirl agreed to her boyfriend's request to take a photo of herself naked and text it to him. A year later when they broke up the boyfriend sent the picture to other students and people outside the school. A similar case involved Jesse Logan an

\footnotetext{
${ }^{14}$ I owe the suggestion of emphasizing the particular valuable role that wisdom as the virtue of phronesis can play in enabling us to exercise good judgment in our online informational choices and conduct, to a reviewer of this paper.
} 
18 year-old from Ohio who hanged herself after an ex-boyfriend distributed nude photos of herself she had sent him by SMS, which her peers used to bully her (Carty 2009). The mask of anonymity afforded by cyberspace communication has allowed for the creation and proliferation of a new form of insidious bullying, that of cyber bullying in schools. A recent case involved cyber bullying by students in a school in Australia. Two girls from the private and prestigious Ascham school for girls in Sydney were expelled from the school after it was established that they had used the network site Myspace to use information and post malicious comments about 31 other girls (Patty 2009). A doctor (general practitioner) in Dubbo, a country town in Australia, posted three videos on You Tube under the pseudonym Funnisean showing himself posing as a female prostitute. This has angered a local member of parliament, who described the doctor's conduct as "unacceptable behaviour" (Benson 2009). More recently, in September 2010, Stephanie Rice, a treble Olympic goldmedallist lost a major sponsorship with Jaguar because of derogatory comments she made on Twitter concerning the South African Rugby team. She had referred to them as "faggots" (Hosking 2010).

The uncritical and sometimes thoughtless dissemination of a lot of trivial and personal information of oneself and others on Social Network Sites (SNS) such as Facebook, Myspace and You Tube as well as through SMS and Twitter, as the above examples illustrate, might be not only not conducive to wisdom and a good life overall, but detrimental to it. For they appear to encourage unreflective, foolish and reckless behavior with no apparent compensating axiological or eudemonic value for oneself, one's "friends" and others. Given the pitfalls of creating and accessing unreflectively information about oneself and others, without any compensating realization of value in relation to one's conception of a good life, a wise person would thus be best served in exercising caution when using digital information. Such overall reflective caution is also in keeping with one of wisdom's essential characteristics, namely, control; that is to say, the ability to narrow down the areas in one's life over which one has little or no control so as to enlarge the areas of our lives that we can order in conformity with our conception of a good life (Kekes 1995). This is a process of self-knowledge, a process of reflection involving judgments "whose aim is to make our character less fortuitous and more deliberate" (Kekes 1995, pp. 127-28). When we allow ourselves to unreflectively misuse digital information of ourselves and others on the Internet and through the use of smart phones, we make ourselves more "fortuitous" and less "deliberate". In so doing, we become hostages to fortune since we no longer have any control over that information, which now for ever floats beyond our control in cyberspace.
Surely such unreflective conduct is not only not wise but can in extreme circumstances be foolish and ultimately self-defeating if, upon careful reflection, it undermines our considered conception of a good life and that of its realization.

A third reason why wisdom is of primary relevance to an enquiry concerning the role that digital information plays in a good life is that some of the issues with regard to the use of digital information qua good life relate not primarily to moral or immoral conduct by individuals towards others but to the prudentially appropriate or inappropriate conduct of the individuals in relation to themselves: or more precisely what is good for them-good for their lives. In short, such conduct might only constitute unwise or foolish behavior and not necessarily unethical conduct, although such unwise conduct may have unforeseen secondary unethical consequences for others. For example, if an individual posts compromising pictures of themselves on Facebook or Myspace that causes no harm to anyone else but themselves, then the matter is not one of ethics but one of wisdom or at least prudence ${ }^{15}$ - how wise or prudent was the individual to do so, if the outcome of their unwise behavior in public cyberspace turned out to be harmful to themselves in some unintended way. Say, as a result of their unwise but not necessarily unethical conduct that individual was fired from a job they enjoyed and relied upon for their self-fulfillment. Just one recent example is that of an upcoming journalist with the Age (a leading newspaper in Australia) who was fired for a series of unsavory but mostly silly "tweets" about various TV personalities and celebrities (Bodey 2010). If the journalist in question was a little wiser she would not have ruined her career by such unwise but not strictly speaking unethical conduct. We can at least assume that no unethical conduct was intended and no harm befell the celebrities in question.

Wisdom as a type of second-order knowledge involves reflection, sound judgment, and understanding in the use and development of information in the form of first-order knowledge (both knowledge-that and knowledge-how) to be applied with the aim of guiding and directing our thoughts and actions in the discovery and achievement of what is of value for us in life, in relation to our overall conception of a good life.

New Media, including the Internet and computers generally have made it possible for us to access and use

\footnotetext{
15 The term prudence used throughout this paper refers to the virtue of prudence conceived as an enabling disposition or trait of character that has the tendency of preventing an individual of engaging in conduct that is likely to cause them harm-that is, conduct unbecoming of a virtuous person. Unlike the term instrumental rationality, which is a non-moral term and refers to the non-moral self-interest of an individual, prudence by contrast refers to the virtuous and hence moral self-interest of an individual person.
} 
extraordinarily and unprecedented large quantities and varieties of information. This is indeed the age of information. However, what seems to follow from our characterization of wisdom above is that the uncritical access and use of so much information without the appropriate reflection, judgment and understanding, might not be conducive to wisdom and consequently might not be conducive to a good life for individuals or societies. Thus, the uncritical accumulation and use of more information is not necessarily conducive to more wisdom (because not essential to it) and hence not more conducive to a good life. On the contrary, sometimes we might be better off with less information rather than more, especially if the former is directed by wisdom (less information) and the latter is not (more information).

Even in the case of critically accessing and using contextualized information, such information might also not be conducive to wisdom and to a good life, if that information is merely used instrumentally without a clear understanding of the ends which that information is intended to achieve or a clear understanding of the value of those ends. Recall that wisdom not only directs the means but also the ends of our actions. Thus the accessing and use of a lot of contextualized information on our iPhone, for example, without a clear understanding of the value of the ends for which that information is to be used, might at best be neutral with regard to the goodness of our lives and worse detrimental to the goodness of our lives if it utilizes too much of our cognitive and social resources for the acquisition of information that ultimately is of little or no axiological or eudemonic value for us personally and for society at large.

\section{Conclusion}

The object of the paper has been to explore how information generally and digital information specifically can be normatively evaluated in relation to the concept of a good life. To that end, the paper developed and applied a meta-theoretical model, the DOIT-Wisdom model, as a groundwork for demonstrating how information can be normatively evaluated, using a cluster of inter-related normative categories, including, the epistemic, ethical, axiological and eudemonic categories, analyzed and defended on the basis of that model. Central to those normative categories is the concept of wisdom, which being at once a meta-epistemological, meta-axiological and meta-eudemonic concept, establishes a direct conceptual link between information and the notion of a good life both for individuals and societies generally. More specifically, wisdom as the paper demonstrated has a particular and important normative relevant role to play in the evaluation of digital information. The cited examples of the dissemination of digital information on the Internet and other digital media in section "The application of wisdom for the normative evaluation of digital information in relation to the concept of a good life" were used illustratively and as proof of concept to demonstrate how the notion of wisdom as the essential conceptual link between information and a good life can be used methodologically to evaluate both axiologically and eudemonically the creation, access, use and dissemination of any type of digital information on the Internet and on computers generally. Some digital informational evaluations such as, for example, the use of Skype to communicate regularly with close friends and family will be positive, given that relationships with friends and family are conducive to a good life and as such, their cultivation and maintenance is generally, wise-worthy. Other digital informational evaluations, such as the examples from Facebook, Myspace and SMS and Twitter above, may prove negative because not conducive to a good life and possibly conducive to a bad life, and therefore not wise-worthy. Hence, wisdom in its theoretical mode but also most importantly in its practical mode as the reflective virtue of phronesis, is essential in enabling us to exercise good judgment in our online behavior, both with regard to our chosen informational means and ends that are conducive to the pursuit and attainment of a valuable good life, for us and for others.

Although descriptively it can be said that we are now living in the age of information, prescriptively we should, if we are wise or at least aspire to be wise, aim at promoting the Age of Wisdom, both for our own sake and that of others, and especially for the sake of future generations who might mistake mere information for knowledge and mere knowledge for wisdom. This paper has argued for a theoretical groundwork for the normative evaluation of information generally, and digital information specifically through the notion of wisdom. No doubt a lot more work must be accomplished in a more extensive examination and evaluation of specific types of good and bad uses of information that daily impact on the lives of people both positively and negatively. As we adapt ourselves to live more and more in the infosphere, including virtual worlds, this becomes a desirable and indeed a necessary task. I hope this is but the beginning of an ongoing research project-a project that extends the scope of Information Ethics to include the all-important Ethics of Wisdom.

Open Access This article is distributed under the terms of the Creative Commons Attribution Noncommercial License which permits any noncommercial use, distribution, and reproduction in any medium, provided the original author(s) and source are credited. 


\section{References}

Aristotle. (1941). Nichomachean ethics, the basic works of Aristotle (pp. 935-1112). New York: Richard McKeon.

Baltes, P. B., \& Smith, J. (1990). Toward a psychology of wisdom and its ontogenesis. In R. J. Sternberg (Ed.), Wisdom: Its nature, origins, and development (pp. 87-120). New York: Cambridge University Press.

Baltes, P. B., Gluck, J., \& Kunzmann, U. (2002). Wisdom: Its structure and function in regulating successful life span development. In C. R. Snyder \& S. J. Lopez (Eds.), Handbook of positive psychology (pp. 327-347). Oxford: Oxford University Press.

Banicki, K. (2009). The Berlin wisdom paradigm: A conceptual analysis of a psychological approach to wisdom. History and Philosophy of Psychology, 11(2), 25-36.

Benson, H. H. (2000). Socratic wisdom: The model of knowledge in Plato's early dialogues. Oxford: Oxford University Press.

Benson, K. (2009). Doctor in hot water for posing as prostitute on YouTube, Sydney morning herald, February, 2, 2009. http://www. smh.com.au/news/national/dubbo-doctor-in-hot-water-for-posingas-prostitute-on-youtube/2009/02/01/1233423045515.html. Accessed 6 Jan 2011.

Bodey, M. (2010). Ousted columnist Catherine Deveny queries age editorial policy after Twitter rants sacking, The Australian, May, 5, 2010. http://www.theaustralian.com.au/business/media/ous ted-columnist-catherine-deveny-queries-age-editorial-policy-aftertwitter-rants-sacking/story-e6frg996-1225862454535. Accessed 10 Jan 2011.

Carty, L. (2009). Parents get sex message, Sydney morning herald, May, 3, 2009. http://www.smh.com.au/news/technology/parentsget-sext-message/2009/05/02/1240982472297.html?page=2. Accessed 6 Jan 2011

Descartes, R. (1979). Principles of philosophy. In Philosophical works of desacartes, (pp. 201-302) (E. Haldane, G. Ross, Eds., Trans.). London: Cambridge University Press.

Dretske, F. (1999). Knowledge and the flow of information. Stanford: CSLI Publications.

Erasmus, D. (1994). In praise of folly (A. H. T. Levi, Ed., B. Radice, Trans.). Penguin Classics.

Finnis, J. (1980). Natural law and natural rights. Oxford: Clarendon Press.

Finnis, J. (1983). Fundamentals of ethics. Oxford: Clarendon Press.

Floridi, L. (2002). What is the philosophy of information? Metaphilosophy, 33, 123-145.

Floridi, L. (2005). Is semantic information meaningful data? Philosophy and Phenomenological Research, LXX, 2.

Floridi, L., \& Sanders, J. W. (2002). Mapping the foundation list debate in computer ethics. Ethics and Information Technology, 4(1), 1-9.

Garrett, R. (1996). Three definitions of wisdom. In R. Lehrer, et al. (Eds.), Knowledge, teaching, and wisdom (pp. 221-232). Dordrecht: Kluwer Academic Publishers.

Gewirth, A. (1978). Reason and morality. Chicago: University of Chicago Press.

Gewirth, A. (1996). The community of rights. Chicago: University of Chicago Press.
Gewirth, A. (1998). Self-fulfillment. Princeton, NJ: Princeton University Press.

Hosking, W. (2010). Gay slur costs stephanie rice jaguar sponsorship deal, herald sun, September 7, 2010. http://www.heraldsun.com. $\mathrm{au} /$ entertainment/confidential/gay-slur-costs-stephanie-rice-jaguarsponsorship-deal/story-e6frf96x-1225914998070. Accessed 6 Jan 2011.

Kekes, J. (1983). Wisdom. American Philosophical Quarterly, 20(3), $277-286$.

Kekes, J. (1995). Moral wisdom and good lives. Ithaca: Cornell University Press.

Kunzmann, U., \& Baltes, P. (2005). The psychology of wisdom: Theoretical and empirical challenges. In R. J. Stenberg \& J. Jordan (Eds.), A handbook of wisdom: Psychological perspectives. New York: Cambridge University Press.

Kvanvig, J. L. (2003). The value of knowledge and the pursuit of understanding. Cambridge: Cambridge University Press.

Lehrer, K., Lum, B. J., Slichta, B. A., \& Smith, N. D. (Eds.). (1996). Knowledge, teaching, and wisdom. Dordrecht: Kluwer Academic Publishers.

Maxwell, N. (2007). From knowledge to wisdom (2nd ed.). London: Pentire Press.

Nozick, R. (1989). What is wisdom and why do philosophers love it so? The examined life (pp. 267-278). New York: Touchstone Press.

Patty, A. (2009). Cyber bullies run amok at top school, Sydney morning herald, May 8, 2009. http://www.smh.com.au/news/ technology/cyber-bullies-run-amok-at-top-school/2009/05/07/124 1289315388.html. Accessed 6 Jan 2011.

Plato. (1978). The Republic. In E. Hamilton \& H. Cairns (Eds.), The collected dialogues of Plato (pp. 575-844). Princeton: Princeton University Press.

Ryan, S. ( 1996). Wisdom. In Lehrer, et al. Knowledge, teaching, and wisdom (pp. 233-242). Dordrecht: Kluwer Academic Publishers.

Ryan, S. (1999). What is wisdom? Philosophical Studies, 93, 119-139.

Ryan, S. (2007). Wisdom. Stanford encyclopedia of philosophy. Accessed 14 June 2010.

Spence, E. (2006). Ethics within reason: A neo-gewirthian approach. Lanham: Lexington Books. (a division of Rowman and Littlefield).

Spence, E. (2009a). The epistemology and ethics of internet information. In A. D'Atri \& D. Sacca (Eds.), Information systems: People, organizations, institutions, and technologies: ItAIS: The Italian association for information systems. Heidelberg: Physica.

Spence, E. (2009b). A universal model for the normative evaluation of internet information. Ethics and Information Technology, 11, 4.

Sternberg, R. J., \& Jordan, J. (2005). A handbook of wisdom: Psychological perspectives. New York: Cambridge University Press.

Tiberius, V. (2008). The reflective life: Living wisely with our limits. Oxford: Oxford University Press.

Vallor, S. (2010). Social networking technology and the virtues. Ethics and Information Technology, 12(2), 157-170.

Varelius, J. (2004). Objective explanations of individual well-being. Journal of Happiness Studies, 5, 73-91.

Vitek, B., \& Jackson, W. (2008). The virtues of ignorance: Complexity, sustainability, and the limits of knowledge. Kentucky: The University Press of Kentucky. 